\title{
Hepatocellular carcinoma in body builders; an emerging rare but serious complication of androgenic anabolic steroid use
}

\author{
Christopher Woodward, Josie Smith, Dean Acreman, and Nagappan Kumar
}

University Hospital Wales, and Public Health Wales, Cardiff, UK

\begin{abstract}
Illicit use of androgenic anabolic steroids (AAS) is a known problem amongst certain groups including body builders and other athletes. Use of these drugs is thought to be high in some areas of South Wales. A number of adverse effects have been associated with use of AAS including the development of hepatic adenomas. There have been a handful of rare cases of the development of hepatocellular carcinoma following AAS use. We report two such cases presenting to the same surgical centre in South Wales within six months. We do this with reference to data from Public Health Wales, including the Harm Reduction Wales Needle and Syringe provision report, which indicate a particularly high rate of use of AAS in the surrounding area. We believe these cases are important from the public health point of view. They demonstrate a rare and not widely known about, but potentially fatal adverse effect of AAS, now becoming prevalent with the high use of these drugs. This is important for doctors to be aware of, but also could form the focus of a public health campaign targeted at AAS users. (Ann Hepatobiliary Pancreat Surg 2019;23:174-177)
\end{abstract}

Key Words: HCC; Anabolic steroids

\section{INTRODUCTION}

Illicit use of androgenic anabolic steroids (AAS) is a known problem amongst some groups, including body builders and other athletes. The full extent of use of these drugs is not clear, due to limited studies. ${ }^{1}$ However use of AAS is suspected to be high in some areas of South Wales. ${ }^{2}$ The Harm Reduction Database Wales: Needle and syringe provision 2015-16 report stated that of the 17,161 individuals accessing needle and syringe provision across Wales; 8,375 (48\%) were primary Image and Performance Enhancing Drug (IPED) users, this category of substances includes $\mathrm{AAS}^{3}$

Here we report of two cases of hepatocellular carcinoma (HCC) developing in young men in South Wales over the past 6 months. Many adverse effects of AAS have been documented. The development of liver cell adenomas is well known. However, there are only very few reports of HCC in patients using AAS. ${ }^{4}$ We feel that a campaign to highlight this potentially lethal complication of
AAS use may deter young persons from engaging in this activity.

\section{CASE}

\section{Case 1}

A 39 year old man, with a background of bodybuilding, initially presented to his doctor with abdominal pain. An ultrasound to investigate the pain showed an incidental liver lesion. He was generally fit and well and the only medical problem he suffered was gastro-oesophageal reflux disease (GORD). He was taking AAS as part of his body building for many years and stopped taking it for 18 months prior to presentation. Further characterisation of the lesion by MRI showed a $19 \mathrm{~cm}$ heterogenous mass, consistent in appearance with hepatocellular carcinoma, within the right liver. A CT of chest abdomen and pelvis did not show definitive evidence of metastatic disease though several small indeterminate lung nodules were seen.

Received: November 14, 2018; Revised: March 3, 2019; Accepted: March 29, 2019

Corresponding author: Christopher Woodward

University Hospital Wales, and Public Health Wales, 19 Nant-Y-Wedal, Cardiff CF143QU, UK

Tel: +44-07964700724, Fax: +44-07964700724, E-mail: chriswoodward91@gmail.com

Copyright (C) 2019 by The Korean Association of Hepato-Biliary-Pancreatic Surgery

This is an Open Access article distributed under the terms of the Creative Commons Attribution Non-Commercial License (http://creativecommons.org/ censes/by-nc/4.0) which permits unrestricted non-commercial use, distribution, and reproduction in any medium, provided the original work is properly cited. Annals of Hepato-Biliary-Pancreatic Surgery • pISSN: 2508-5778 - eISSN: 2508-5859 
Surgery was carried out as a potentially curative treatment. A large very vascular tumour was found at surgery. This was resected by a right hemihepatectomy using the anterior approach to prevent tumour rupture. Histological examination showed that this was a HCC with clear margins. The patient has had a CT chest, abdomen and pelvis 3 months after the resection and there is no change in the indeterminate nodules in the lung or any recurrence in the liver.

\section{Case 2}

A 28 year old man, another body builder, presented to the emergency department with epigastric pain. Imaging showed several liver lesions with bleeding into the lesion in the left liver. He was referred to our tertiary liver clinic.

He was a fit and well young man. However, he was treated and discharged 5 years ago for dilated cardiomyopathy. He did not have any cardiac symptoms now. The cardiomyopathy was thought to be related to AAS use as well. He had an extensive history of using AAS for more than 5 years. He had also used growth hormone injections.
When seen in the liver clinic, he had to be admitted to the hospital because of the severe pain he had that could not be controlled with narcotic analgesics.

Imaging (Fig. 1) showed multiple hypervascular masses in the liver. There was a $225 \mathrm{~mm}$ mass occupying segment 2 and 3 and another $135 \mathrm{~mm}$ pedunculated mass from segment $4 \mathrm{~b}$. Liver biopsy performed in the referring hospital had shown an adenoma. The treatment options were liver resection to relieve pain or consider liver transplantation. He may not have been a candidate for liver transplantation as he will not fit in the UK criteria for transplantation. Therefore a resection was planned mainly to relieve pain.

He had an open left lateral sectionectomy and resection of the pedunculated mass in segment $4 b$ of liver (Fig. 2). The specimen weighed 4 kilograms.

Histology revealed a well differentiated HCC. He has had a further CT chest abdomen and pelvis 3 months after the operation which showed some regression of the other adenomas in the liver. This may be due to the cessation of the AAS use now.
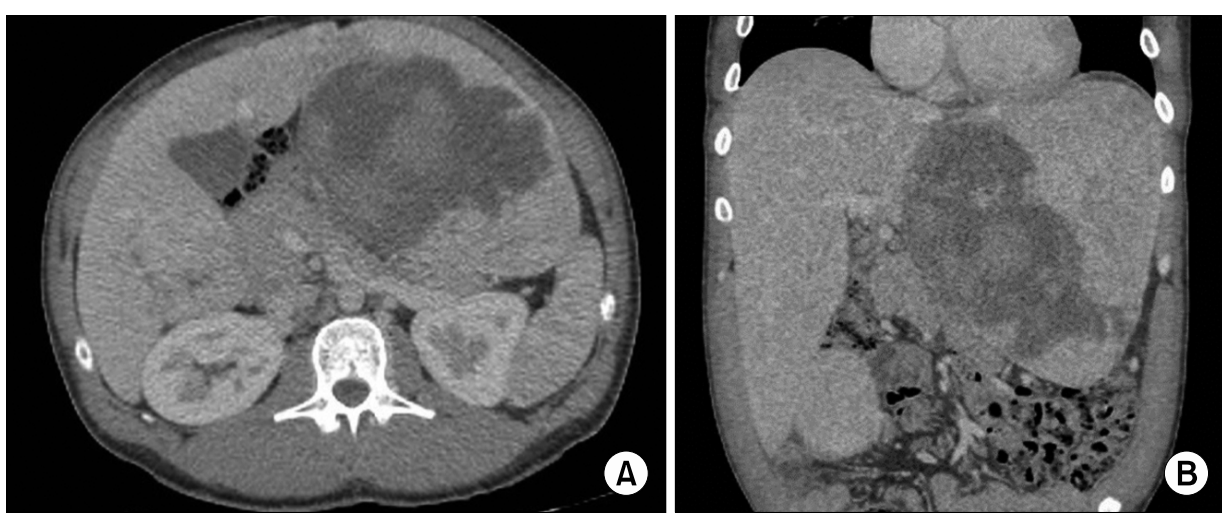

Fig. 1. Preoperative computed tomography images of the case 2. Axial image (A) and coronal image (B) showing multiple hypervascular lesions within the liver. Masses occupy the segment 2 and 3, with another pedunculated mass arising from the segment 3 .
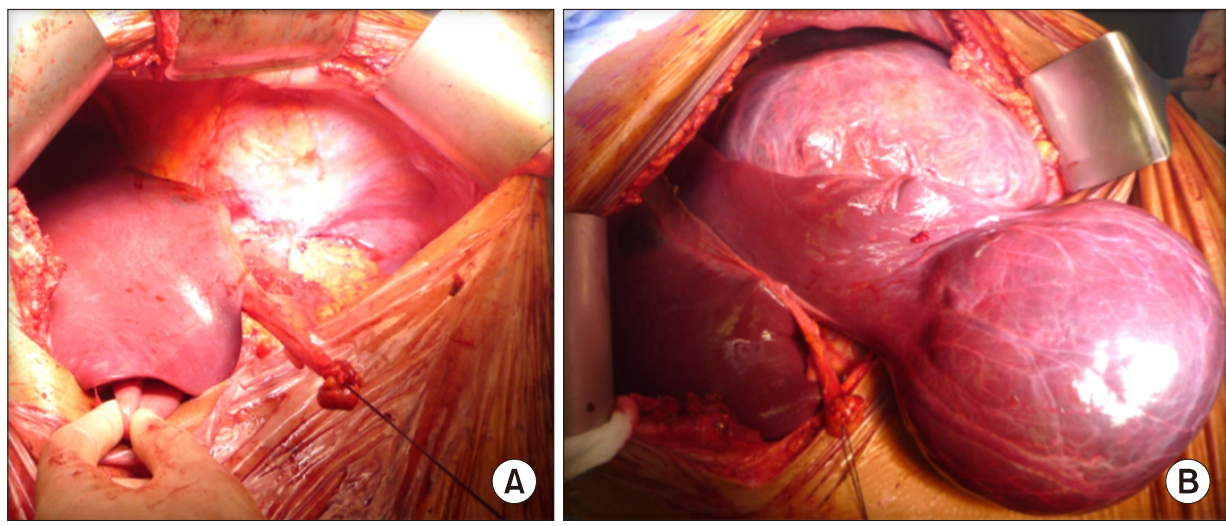

Fig. 2. Intraoperative photographs of the case 2. (A) A left lateral sectionectomy was performed along with removal of the pedunculated mass arising from the segment 3. (B) A large pedunculated lesion can be seen clearly. 


\section{DISCUSSION}

Cases of HCC associated with AAS use are rare. HCC has been documented as a complication of legal use of such drugs in the treatment of haematological disorders such as Fanconi's anaemia. ${ }^{5}$ However, as for illicit use of anabolic steroids, a handful of cases of young males involved in body building, developing HCC following anabolic steroid use have been reported. ${ }^{6-8}$ It is therefore significant to be able to report a series of two such cases of HCC in body builders, arising within the same surgical centre.

It is well known that AAS use is associated with a number of complications, ${ }^{4}$ some of which may be well known amongst the general population. It is well established that anabolic steroid use is associated with the development of hepatocellular adenomas. In general it is estimated that the transformation rate of hepatocellular adenomas to HCC may be around $4 \%{ }^{9}$ Therefore a small number of drug users might be expected to develop HCC within a large enough population. Alternatively it may be the case that in patients using anabolic steroids, HCC may develop de novo, rather than through an adenoma - carcinoma transformation pathway. Cases of HCC associated with a testosterone receptor have been reported, and thus this may be part of the mechanism of development and growth of such tumours. ${ }^{8}$

AAS use is not insignificant within the UK. The Home Office national crime survey 2015/16 estimates anabolic steroids are used by $0.2 \%$ of the population aged 16 to 59. However use of these drugs may well be much higher in those involved in bodybuilding, especially those using so called "hard core" gyms. ${ }^{10,11}$ It is unclear quite how widespread anabolic steroid use may be within such groups as only fairly limited epidemiological studies have been conducted. However anabolic steroid use may be widespread in the South Wales area, where these cases occur. A regional study of gyms found a surprisingly high prevalence of anabolic steroid use. ${ }^{2}$ It is therefore important that these two cases should be taken note of, not only as further evidence of possible adverse effects of anabolic steroid use, but from the public health point of view. These cases, though they are examples of a rare pathology, involve a malignant disease, so should very much be considered when thinking about the potential harm of these drugs on the population. These cases are also useful in considering publicising the dangers of anabolic steroid use, due to the very serious nature of the disease. Potentially some body builders may be deterred from using these drugs if the possibility of developing HCC was more widely known about. Many may be put off taking such drugs by considering the risk of developing lesions such as those described in these cases. Concern is heightened by the fact that $69 \%$ of participants of the 2015 National IPED survey (a survey of 663 AAS users) waited for symptoms of adverse effects to go away on their own, with only $9.4 \%$ seeking treatment from a general practitioner and less than 10 participants reporting use of facilities including accident and emergency departments, NHS drop in centres and hospitals for treatment relating to their IPED use. ${ }^{10}$ It is important then that both physicians and potential users be made aware of the risks associated with these drugs especially development of HCC which may not be widely known about at present.

These two cases of young men from the South Wales area developing HCC following anabolic steroid use provide further evidence of the development of this malignancy as a result of these drugs. Though this pathology is a rare one, its seriousness is such that it should be considered when thinking about the harmful effects of these drugs within the population groups using them. The cases highlight the need not only for physicians to be aware of this adverse effect, but for wider publicity amongst populations who are using anabolic steroids. There may be need for a targeted public health campaign to raise further awareness of adverse effects of anabolic steroids, including the development of HCC.

\section{REFERENCES}

1. Baker JS, Graham MR, Davies B. Steroid and prescription medicine abuse in the health and fitness community: a regional study. Eur J Intern Med 2006;17:479-484.

2. Casavant MJ, Blake K, Griffith J, Yates A, Copley LM. Consequences of use of anabolic androgenic steroids. Pediatr Clin North Am 2007;54:677-690, x.

3. Public Health Wales. Harm reduction database wales: needle and syringe provision 2015-16. Cardiff: Public Health Wales, 2016.

4. Velazquez I, Alter BP. Androgens and liver tumors: Fanconi's anemia and non-Fanconi's conditions. Am J Hematol 2004;77: 257-267.

5. Gorayski P, Thompson CH, Subhash HS, Thomas AC. Hepatocellular carcinoma associated with recreational anabolic steroid use. Br J Sports Med 2008;42:74-75; discussion 75. 
6. Hardt A, Stippel D, Odenthal M, Hölscher AH, Dienes HP, Drebber U. Development of hepatocellular carcinoma associated with anabolic androgenic steroid abuse in a young bodybuilder: a case report. Case Rep Pathol 2012;2012:195607.

7. Solbach P, Potthoff A, Raatschen HJ, Soudah B, Lehmann U, Schneider A, et al. Testosterone-receptor positive hepatocellular carcinoma in a 29 -year old bodybuilder with a history of anabolic androgenic steroid abuse: a case report. BMC Gastroenterol 2015;15:60.

8. Stoot JH, Coelen RJ, De Jong MC, Dejong CH. Malignant transformation of hepatocellular adenomas into hepatocellular carci- nomas: a systematic review including more than 1600 adenoma cases. HPB (Oxford) 2010;12:509-522.

9. Korika P. Anabolic steroid use in Britain. Int J Drug Poicy 1994;5:6-10.

10. Lenehan P, Bellis M, McVeigh J. A study of anabolic steroid use in the North West of England. J Perform Enhanc Drugs 1996;1:57-70.

11. McVeigh J, Bates G, Chandler M. Steroids and image enhancing drugs: 2014 survey results. Liverpool: Centre for Public Health, Liverpool John Moores University, 2015. 